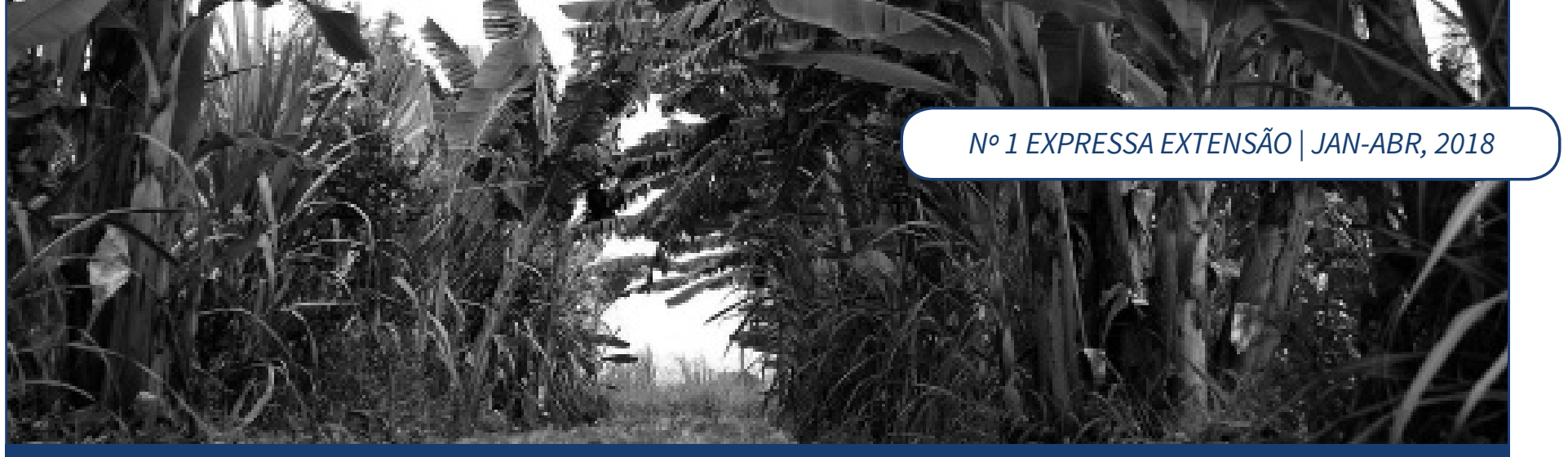

\title{
A TRANSIÇÃO AGROECOLÓGICA EM GRUPOS RURAIS DE ECONOMIA SOLIDÁRIA ATRAVÉS DA EXTENSÃO RURAL UNIVERSITÁRIA
}

THE AGROECOLOGICAL TRANSITION IN RURAL GROUPS OF SOLIDARITY ECONOMY THROUGH RURAL UNIVERSITY EXTENSION

\section{Décio Souza Cotrim ${ }^{1}$ Lucio André de Oliveira Fernandes ${ }^{2}$ Fernanda Dias dos Santos da Silva ${ }^{3}$}

\section{RESUMO}

O projeto Tecnologia Sociais e Economia Solidária-TECSOL possui dentro de suas ações um esforço voltado à comercialização, em circuitos curtos, de alimentos ecológicos produzidos por grupos de agricultores que se encontram em processo detransição agroecológicaintitulado feira virtual. Oobjetivo desse artigo éanalisar as virtudes e os limites do processo de extensão rural universitária desenvolvidos pelo TECSOL junto as famílias envolvidas na experiência. Metodologicamente foram realizadas entrevistas estruturadas para os consumidores que adquirem os alimentos na feira virtual e entrevistas semiestruturadas com as famílias de agricultores envolvidas. Como resultados se percebeu que como virtudesa experiência desenvolveu a concretude da realização de uma feira virtual por um longo período vencendo os problemas cotidianos de um processo desse tipo; os alunos envolvidos na extensão rural universitária desenvolveram características de profissionais participativos, agroecológicos e solidários; e, os agricultores apresentam elementos que atestam um real processo de transição agroecológica. Como limites do processo apontou-se a característica da insegurança dos alunos na ação de extensão rural universitária; e principalmente, a existência de muitas estratégias do ambiente hostil do mercado geral que produz dificuldades para consumidores e agricultores envolvido em sistemas de economia solidária.

Palavras-Chave: Agroecologia. Extensão rural. Participativo. Desenvolvimento rural.

\footnotetext{
${ }^{1}$ Doutor em Desenvolvimento Rural. Programa de Pós-graduação em Desenvolvimento Territorial-DTSA. Faculdade de Agronomia Eliseu Maciel-Universidade Federal de Pelotas, Campus Universitário, S/N - CEP 96160-000, Pelotas, Rio Grande do Sul, Brasil. E-mail: deciocotrim@yahoo.com.br. ${ }^{2}$ Professor Doutor, PhD Development Policy and Management University Manchester UK. Faculdade de Agronomia Eliseu Maciel-Universidade Federal de Pelotas, Campus Universitário, S/N - CEP 96160-000, Pelotas, Rio Grande do Sul, Brasil. E-mail: lucio.fernandes@ ufpel.edu.br. ${ }^{3}$ Mestranda do Programa de Pós-Graduação em Sociologia Universidade Federal do Rio Grande do Sul, Rua Caetés, 211 CEP 92010-150 Canoas, Rio Grande do Sul, Brasil: E-mail: silva.fds@outlook.com.
} 


\begin{abstract}
The Social Technology and Solidarity Economy-TECSOL project has in its actions an effort aimed at the marketing, in short circuits, of organic food produced by groups of farmers who are in the process of agro-ecological transition called virtual fair. The objective of this article is to analyze the virtues and limits of the rural extension process developed by TECSOL among the families involved in the experience. Methodologically, structured interviews were conducted for consumers who buy food at the virtual fair and semi-structured interviews with the families of farmers involved. As results it was realized that as virtues the experience developed the concretion of the accomplishment of a virtual fair for a long period overcoming the daily problems of such a process; the students involved in rural university extension developed characteristics of participatory, agroecological and solidarity professionals; and farmers present elements that attest to a real process of agroecological transition. As limits of the process the characteristic of the insecurity of the students in the action of rural university extension was pointed out; and especially the existence of many strategies of the hostile environment of the general market that produces difficulties for consumers and farmers involved in systems of solidarity economy.
\end{abstract}

Keywords: Agroecology. Rural extension. Participatory. Rural development.

\title{
INTRODUÇÃO
}

No âmbito da Universidade Federal de Pelotas-UFPEL o núcleo de pesquisa-ensino-extensão intitulado Tecnologias Sociais e Economia SolidáriaTECSOL existe desde 2011, através de um esforço do corpo de professores, alunos e técnicos no sentido de apoiar um conjunto de empreendimentos da economia solidária que gravitavam em torno do grupo. Essa experiência é desenvolvida em Pelotas-RS abrangendo também os municípios de Morro Redondo e Canguçu.

O TECSOL congrega grupos de economia solidária rurais e urbanos. O público dos empreendimentos rurais é formado por agricultores familiares que estão em um estrato de fragilidade social. Esses produtores estão emersos dentro de um conjunto de comunidade rurais de agricultores familiares, existindo nos três municípios envolvidos na experiência um total de 12.641 estabelecimentos dessa categoria social (IBGE, 2006). 
Os agricultores, em sua grande maioria, recebem assistência técnica da EMATER/RS einvariavelmente encontram-se ligados à indústria fumageira na produção do tabaco. Em pesquisa realizada com agricultores dessa região foi identificado que $65 \%$ deles possuem interesse em diversificar a produção agropecuária no sentido de deixar de plantar fumo (COTRIM; CANEVER, 2016).

O trabalho desenvolvido pelo TECSOL junto aos agricultores familiares se caracteriza como um processo de extensão rural universitária para a transição agroecológica. A agroecologia aqui é entendida enquanto uma matriz científica que fornece elementos para um diálogo de saberes entres os atores na construção do conhecimento. Nesse aspecto existem esforços para construção de um conhecimento agroecológico coletivo pautado por uma ação dos extensionistas em uma perspectiva participativa. A extensão rural universitária é compreendida como um assessoramento, realizado por alunos universitários, aos agricultores familiares sendo coordenado pelos professores do TECSOL.

Os grupos dos agricultores familiares produzem alimentos de base orgânica para o seu consumo e canalizam o excedente para canais de comercialização de proximidade. Na atualidade eles acessam dois espaços de comercialização via TECSOL, sendo eles a feira presencial Bem na Terra e a feira virtual. Ambos são ambientes que conectam os agricultores com grupos de consumidores conscientes e solidários que valorizam os princípios desenvolvidos de economia solidária-agroecologia ${ }^{4}$. A feira presencial Bem na Terra se caracteriza por um espaço de comercialização que se realiza ordinariamente toda semana e extraordinariamente em eventos. A feira virtual Bem da Terra é um mecanismo de comercialização para consumidores previamente organizados em núcleos de consumo responsável. Eles encomendam semanalmente os produtos de sua preferência através de uma plataforma virtual.

$\mathrm{Na}$ atualidade os desafios do TECSOL são muitos. Várias questões emergem entre os agricultores e extensionistas que vivem o seu dia a dia. Entre esses alguns aspectos merecem destaque pela sua premência e demanda do grupo a necessidade de continuidade e aprimoramento da ação de alunos extensionistasno processo de extensão rural universitária, a manutenção e ampliação dos mercados para esse tipo de empreendimento, a preocupação com a produção de alimentos saudáveis através de um sistema de produção agropecuário de base orgânica, o relacionamento entre grupos urbanos e rurais da economia solidária, entre muitos outros.

\footnotetext{
${ }^{4}$ Para mais informações ver: http://bemdaterra.org/rede-de-consumidores/
} 
Dentro dessa problemática foi escolhido como objetivo desse artigo a análisedas virtudes e fragilidades do processo de extensão rural universitária, voltado a transição agroecológica, nos grupos rurais da economia solidária ligados ao TECSOL da feira virtual.

\section{METODOLOGIA}

A metodologia utilizada nesta pesquisa configura-se como um estudo de caso qualitativo com característica exploratória. Quanto à técnica configura-se como pesquisa de campo uma vez que a mesma permite integração de diferentes abordagens e técnicas - qualitativas e quantitativas - em um mesmo estudo, além da observação dos fatos tal qual ocorrem (GIL, 2002).

A coleta de dados foi realizada através de questionários estruturados e semiestruturados, complementados com observações participante dos autores, e a análise se deu em conjunto teórico expresso no texto.

Para o atendimento ao objetivo principal foram realizadas um conjunto de entrevistas. Para a delimitação das características dos consumidores, dentro da feira virtual, foram aplicadossetenta e nove questionários estruturados. Para a aferição das percepções dos grupos de agricultores foram realizadas vinte entrevistas semiestruturadas em todos os grupos rurais de economia solidária.

Com os agricultores a investigação ocorreu a partir de entrevistas familiares ou individuais, no formato semiestruturado. Esse tipo de entrevista permitiu uma conversa informal entre pesquisador e entrevistado balizada por um conjunto de temas pré-definidos no qual foi explorado um conjugado de pontos de interesse sobre o assunto (BONI; QUARESMA, 2005).

A técnica utilizada complementarmente foi a Observação Participante em razão da convivência cotidiana com estudantes universitários e os agricultores. Essa técnica consiste no exercício da percepção, sua explicitação mental, sua memorização e anotação de determinado evento no desenrolar da pesquisa (BEAUD; WEBER, 2007). 


\section{REFERENCIAL TEÓRICO}

Para sustentar teoricamente esse estudo se entende necessário a explicitação dos conceitos adotados de Agroecologia e transição agroecológica, bem como, de economia solidária e circuitos curtos de comercialização.

\section{Agroecologia e transição agroecológica}

O conceito de Agroecologia está em construção, tendo vários autores que contribuem para uma ampla formatação. Inicialmente, cabe salientar uma confusão conceitual observável em vários espaços acadêmicos. Mesmo que a palavra agroecologia lembre em um impulso inicial, estilos de agriculturas menos agressivos, não se pode confundi-la com um tipo de agricultura alternativa. Nesse mesmo sentido, a agroecologia não é somente uma agricultura socialmente justa, ou uma agricultura sem a destruição do meio ambiente, ou ainda uma agricultura sem exclusão de ninguém. Essas interpretações expressam reducionismos do sentido amplo do conceito (CAPORAL; COSTABEBER, 2002).

Outra fonte de interpretações emerge dos movimentos pragmáticos da agricultura alternativa. Com o passar do tempo, o termo "alternativo" foi sendo substituído pela expressão agroecologia, encontrada em publicações de livros antecedentes à fase prática. Nesse caminho, as noções de uma agricultura de base ecológica, o respeito a dimensão ambiental e a consideração às práticas tradicionais dos agricultores, passou a ser chamada também de agroecologia (DAL SOGLIO, 2012).

Guzmán e Molina (1996) dizem que a agroecologia se constitui em um espaço de estudos, que requer o manejo ecológico dos recursos naturais, para, por meio de uma ação social coletiva de caráter participativo, de um enfoque holístico e uma estratégia sistêmica, reconduzir o curso alterado da co-evolução social ecológica.

A agroecologia é uma nova estrutura conceitual em construção, onde existe uma integração dos campos da ciência, de maneira a oferecer um conjunto de instrumentos para o estudo das múltiplas relações que podem ter um lugar nas multíplices inerentes ao desenvolvimento rural. 
A agroecologia recupera estudos dos camponeses, que levam em conta o conhecimento local, ou seja, a co-evolução das comunidades locais com o agroecossistema. Ela se nutre de outros espaços do conhecimento, assim como de saberes dos próprios camponeses, o que permite a formação de um marco conceitual e metodológico (CAPORAL, 1998).

Altieri (1989), por outro lado, afirma que agroecologia é a disciplina científica que aproxima os estudos de agricultura em uma perspectiva ecológica, sendo definida como uma estrutura teórica destinada a compreender os processos agrícolas de ampla maneira. Ela está centrada no entendimento das inter-relações dos elementos componentes do agroecossistema e as dinâmicas complexas do processo ecológico.

Segundo Gliessman (2005), a agroecologia pode ser definida como a aplicação dos princípios e conceitos ecológicos aos desenhos e gestão dos agroecossistemas sustentáveis. Ela se apresenta como um enfoque teórico que propicia as bases científicas para o desenvolvimento da agricultura.

Norgaard (1989), seguindo o caminho dos estudos da ecologia humana e da etnoecologia, afirma que a diferença mais importante entre a visão agroecológica de mundo e a ciência ocidental, é que os agroecologistas veem as pessoas como partes do sistema local em desenvolvimento. Os estudos em agroecologia interpretam sistemas complexos que foram desenvolvidos com pessoas fazendo parte de um único processo. Os sistemas sociais e biológicos co-evoluíram de tal maneira que a sustentação de cada um depende estruturalmente do outro, ou seja, um agroecossistema.

O agroecossistema, nessa visão, para além do sistema biológico, inclui também o sistema de conhecimento, o sistema de valores, a organização social e a tecnologia dos atores. Neste contexto não existem verdades universais, mas cada agroecossistema tem uma história co-evolutiva diferente. Essas mudanças refletem as decisões das comunidades condicionadas por seus valores, crenças, organização e tecnologia.

Segundo Costabeber (1998), a agroecologia é um marco teórico, cujo fim é amenizar os processos agrícolas de maneira mais ampla. Na perspectiva agroecológica, a transição assume uma característica multilinear, sendo assentada nas necessidades e potencialidades locais. $O$ agricultor assume o papel de sujeito ativo na determinação e construção de suas opções futuras. 
Pensando na transição agroecológica, Buttel (1995) aponta a existência de transição da agricultura que se coloca em curso a partir da identificação dos elementos de desintegração do modelo tecnológico genérico. A degradação ambiental decorrente da faseda modernização da agricultura, salientada pela erosão dos solos, contaminação das águas e a contaminação dos alimentos com os venenos, são problemas centrais do modelo atual. Por outro lado, a ampliação na sociedade do debate em torno da necessidade de ecologização da agricultura, demarca o inícioda fase de transição agroecológica.

Em uma ótica socioambiental, nesse período se identifica que o processo de modernização da agricultura ultrapassou os limites ambientais, técnicos e sociais dos agroecossistemas, levando a agricultura ao um patamar insustentável. Os debates sobre os limites ecológicos e sociais do processo de desenvolvimento se desenrolavam em âmbito mundial (ALMEIDA, 1999).

Desde o início do século XX, se configurava uma resistência ao modelo de modernização da agricultura, mas, que tomou força após a década de 1970. Esse movimento apontava a necessária preocupação com os aspectos ecológicos e sociais no desenvolvimento, e levantava a importância da agricultura familiar com lócus desse processo (ALMEIDA, 1999).

O processo de modernização da agricultura ao mesmo tempo em que propiciou o crescimento do agronegócio, levou uma massa de agricultores para exclusão. Nessa fase, grupos de técnicos independentes das estruturas governamentais, se aliaram aos agricultores na busca de um modo de agricultura diferente do padrão hegemônico da época, sobre as premissas da chamada agricultura alternativa (DAL SOGLIO, 2012).

Às margens da academia e da própria pesquisa oficial, emergiram os movimentos pragmáticos que desenvolveram métodos e técnicas adaptadas aos agricultores, considerando as nuances de cada agroecossistema, ou seja, as realidades sociais, econômicas e ecológicas. Esses podem ser considerados os precursores dos estudos agroecológicos ligados fundamentalmente às organizações não governamentais-ONG (DAL SÓGLIO; LEMOS, 2009).

A ideia de uma extensão rural universitária focada na transição agroecológica se configura como sendo uma vertente atual desse longo processo descrito. O reconhecimento da fragilidade social dos grupos rurais de agricultores indica 
que essas famílias não aderiram ao pacote da modernização da agricultura e permanecem na contra hegemonia do processo. Elementos tecnológicos e metodológicos externos, frutos do ambiente do entorno, penetraram nos itinerários técnicos dos agricultores e o seu reconhecimento e reconversão são elementos chaves do processo de transição agroecológica.

\section{Economia solidária ecircuitos curtos de comercialização}

A economia solidária caracteriza-se como um fenômeno econômico, social e político, nascido das contradições do sistema capitalista e animado por valores éticos baseados na solidariedade, na cooperação, na autogestão e na sustentabilidade, cujo resultado é um lento e persistente processo de acumulação social e solidária que orienta e estrutura novas formas de produzir, de distribuir e de consumir, alternativas ao mercado geral de características capitalista e coerentes com os valores que a animam (RAZETO, 1984; SINGER, 1998; CORAGGIO, 2002).

A base teórica da economia solidária pretende compreender o fenômeno sócio-econômico-político que vem se desenvolvendo na sociedade. Este processo de acumulação solidária é realizado imerso num ambiente hostil, ou seja, dentrodas relações de mercado geral de tipo capitalista, marcada pela competição econômica, pela exclusão social, pelas relações hierárquicas de poder (heteronômica) e pela insustentabilidade (CRUZ, 2011).

O desafio da economia solidária é romper as estruturas culturais e ideológicas que organizam este ambiente hostil e propiciar o nascimento e desenvolvimento de suas formas alternativas do fazer econômico dos empreendimentos e redes de produção, de distribuição e de consumo do ponto de vista solidário (TIRIBA, 2001; NUNES, 2009).

Segundo Gaiger (2004), as experiências analisadas dos processos de economia solidária permitem apontar para uma relação entre a natureza participativa e um necessário caráter comunitário. Os processos de tomada de decisão, para serem participativos, exigem relações pessoais e de inter reconhecimento. Passa a ser necessária a articulação de interesses e projetos que reúnam diferentes grupos de atores, mas com a preservaçãoda autonomia e da capacidade de iniciativa. 
Dessa forma, a construção de circuitos curtos de comérciotende a reverter a lógica concentradora do circuito convencional de produção-distribuição-consumo oferecendo uma alternativa sustentável de economia (PISTELLI; ZERBINI, 2004).

Segundo Cruz (2011) Os circuitos convencionais do mercado geral capitalistas são caracterizados por ganhos de produção em escala, graças ao uso intensivo de capital (grandes áreas de monocultivos, emprego intensivo de maquinário e de insumos químicos); pelo armazenamento por processamento industrial, com emprego de mais insumos mecânicos, energéticos e químicos; pela distribuição global através de circuitos de comércio de longa distância (nacionais e internacionais); pelo consumo indiscriminado, alavancado pela publicidade e propaganda e marcado pelo desperdício, pela desatenção à saúde e pela geração massiva de resíduos desnecessários e contaminantes.

A ideia dos circuitos curto de comércio propiciaa construção de uma nova lógica de produção-distribuição-consumo, caracterizada produção associada, em escala adequada à demanda local, de unidades produtivas autogeridas (grupos de agricultores familiares e de empreendimentos econômicos solidários), intensivas em trabalho e em insumos renováveis; pelo armazenamento de curta duração, auxiliado por tecnologias sociais sustentáveis; pela distribuição local e regional, com o emprego de um mínimo de insumos mecânicos e energéticos; pelo consumo consciente (ético e responsável), referenciado nas necessidades sociais efetivas e marcado pelo compromisso do consumidor com a atenção à saúde e ao bem-estar, com a preservação ambiental e redução de resíduos, com a economia local e, finalmente, com a valorização da produção associada (CRUZ, 2011).

\section{RESULTADOS E DISCUSSÕES}

\section{Delimitação e análise do espaço empírico}

O foco analítico desse artigo é o processo de extensão rural universitária que ocorre no âmbito do TECSOL voltada a transição agroecológica dos agricultores componentes dos empreendimentos rurais de economia solidária. 
Para uma compreensão espacial do empírico os seis grupos, formados por vintefamílias de agricultores, estão alocados em propriedades rurais dos municípios de Pelotas, Morro Redondo e Canguçu, no extremo sul do Rio Grande do Sul. Essas propriedades são interligadas por estradas vicinais e perfazem aproximadamente duzentos quilômetros de distância entre todas. Esses grupos intitulam-se: UNAIC (União das Associações do Interior de Canguçu), Grupo Colônia Maciel, Grupo Amoresa, Grupo Silveira, Grupo Germinar e Grupo São Domingos.

Os empreendimentos dos agricultores familiares produzem alimentos de base orgânica para o seu consumo e canalizam o excedente para canais de comercialização de proximidade. Eles são proprietários e moradores de pequenos espaços de terra, utilizam mão de obra familiar e centram sua ação agropecuária em hortigranjeiros, produção de leite e aviários coloniais. Também processam minimamente alimentos, possuem indústrias caseiras e alguns construíram agroindústrias familiares voltadas para doces, compotas e panificados. São percebidas estratégias de pluriatividades dentro dessas famílias como venda ocasional de mão de obra e atividades não agrícolas.

Através das entrevistas realizadas categorizou-se que eles são agricultores familiares que estão em processo de transição agroecológica devido a variadas motivações. Alguns deles plantavam tabaco e em razão do excessivo esforço físico, alto grau de comprometimento do calendário anual de atividades (o fumo ocupa a famíliaaproximadamente trezentos dias por ano) e do envenenamento da família com agrotóxicos resolveram buscar alternativas ancoradas em mercados de proximidades e agroecológicos. Outros estão na etapa da aposentadoria rural e decidiram pela manutenção de um conjunto de atividades de menor impacto físico e escoamento em mercados locais. Uma terceira tipificação são os neorurais caracterizados por famílias que recentemente ocuparam o espaço rural para iniciar trabalhos na agricultura e trazem uma concepção inicial voltada a produção de base orgânica.

Essa tipificação produz um grupo heterogêneo de práticas nas propriedades bem como nos seus projetos de vida e consequentemente diferenciadas demandas para a extensão rural universitária. Os agricultores com idade mais avançada demandam alternativas de manejo e de produção com baixo impacto físico, pois muitas vezes estão sozinhos na propriedade. O grupo da reconversão do tabaco busca rendimento econômicos que possam fazer frente ao patamar do fumo, mas sem os riscos à saúde com o uso de venenos. Os neorurais são pessoas 
com baixa experiência acumulada na agricultura e demandam processos básicos.

Esses agricultores se relacionam cotidianamente com vários mediadores sociais que desenvolvem extensão rural (EMATER/RS, Embrapa, ONG) e também ofertam seus produtos em variados mercados entre os vizinhos, feiras locais, atravessadores, entre outros. A ação dos extensionistas do TECSOL e os volumes comercializados na feira virtual Bem da Terra podem ser considerados complementares dentro das estratégias de reprodução social dessas famílias.

Para a compreensão da dinâmica do processo de comercialização é importante entender a rotina da feira virtual. Essacomeça no início da semana com a oferta, pelos agricultores, dos alimentos e das quantidades individuais disponíveis para os consumidores. Isso é feito através de telefone, mensagens, whatsapp, facebook para os bolsistas do TECSOL que coordenam essa etapa. Esses alimentam o sistema eletrônico que é disponibilizado aos consumidores. Os consumidores escolhem suas compras na internet até quinta-feira. Essa demanda é compactada e devolvidas aos agricultores. No sábado, de madrugada, o transportador oficial dos agricultores da feira virtual carrega os alimentos e entrega em um ponto físico na cidade de Pelotas. O pagamento é feito por meio eletrônico.

Com base no levantamento realizado com os setenta e nove consumidores da feira virtual foi avaliado seu perfil, sendo que essesse distribuem no percentual de $21,5 \%$ dentro da faixa etária entre 16 a 24 anos, $24 \%$ de 25 a 30 anos, $32,9 \%$ de 31 a 40 anos e $21,6 \%$ maiores de 40 anos. Aproximadamente metade deles (47\%) moram no centro de Pelotas, próximo ao centro de distribuição. E, as ocupações principais são servidor/professor da Universidade com percentual de $33 \%$ e estudante com $30 \%$.

Completando a descrição, o terceiro grupo de atores nesse processo, além dos agricultores e consumidores, são os estudantes responsáveis pela extensão rural universitária, bem como os professores que os acompanham. Eles são bolsistas do projeto TECSOL e estudantes do curso de graduação em Agronomia, Veterinária e Gestão Ambiental da UFPEL, normalmente são urbanos e com experiência prática reduzida.

A extensão rural universitária é um processo de acompanhamento dos agricultores individualmente e dentro de seus grupos rurais de economia solidá- 
ria. A ação ocorre em dois grandes âmbitos, ou seja, na organização do grupo a partir dos princípios da economia solidária e na ecologização dos seus sistemas de produção formado por cultivos e criações.

Esse procedimento de extensão rural universitário está assentado em princípios participativos onde os agricultores e os extensionistas são considerados atores dentro de uma arena horizontal de construção do conhecimento (LONG,2001). A partir desse arcabouço as técnicas mais utilizadas são as visitas técnicas as propriedades e o "encontrão".

A visita técnica é um procedimento cotidiano de acompanhamento dos agricultores durante o desenvolvimento do seu itinerário técnico, ou seja, visitasaos cultivos, as criações e a industrialização caseira dos alimentos nos momentos em que estão ocorrendo as atividades. A dinâmica das vistas dos extensionistas a família dos agricultores é semanal.

Essa técnica aproveita a noção de comunidade rural e exercita a prática de uma visita aos moldes de um encontro social. Nessa o agricultor abre as portas de sua casa para receber um amigo e conversar sobre o cotidiano. Os extensionistas aproveitam essa característica social e conduzem a conversa para os caminhos da relação com a produção, o processamento e a comercialização na feira virtual. Para viabilizar essa ação os bolsistas têm a sua disposição um veículo do TECSOL e motorista da Universidade.

A técnica do "encontrão" é um exercício metodológico de construção coletiva do conhecimento. De tempos em tempos (normalmente semestralmente) os agricultores são entusiasmados a se encontrem em dado local, durante um dia inteiro, para desenvolverem um debate coletivo de seus problemas, quer sejam eles tecnológicos, organizacionais ou de comercialização. A responsabilidade da animação e dinamização do processo é dos extensionistas, mas a condução dos momentos dialógicos é coletiva entre todos os atores. Nessas ocasiões é muito comum um agricultor apresentar ao grupo uma forma de cultivo, de adubação ou um procedimento, gerando um processo horizontal de debate e propiciando um momento de construção do conhecimento agroecológico.

O "encontrão" do ponto de vista teórico está diametralmente oposto a posição de uma difusão de tecnologias, aos moldes da modernização da agricultura, onde o conhecimento tecnológico externose sobrepõe ao saber do grupo sendo 
difundido na forma de receituário. A ideia da técnica é um encontro de saberes entre os agricultores, os técnicos participantes, os extensionistas e os professores em processo horizontal de debate. Muitas instituições parceiras (Embrapa, EMATER/RS, ONG) participam desse momento coletivo.

De forma estratégica os bolsistas do projeto TECSOL tem semanalmente um momento de reunião com os professores para relato das atividades ocorridas, análise dos processos, levantamento das demandas e planejamento da próxima semana. A ação dos professores se caracteriza pela orientação na condução dos processos e a reflexão sobre os referenciais teóricos da economia solidária e da agroecologia. Nesse sentido os professores buscam a formação dos alunos com perfil de extensionistas rurais participativos e conscientes do seu papel junto as organizações dos agricultores.

\section{Análise das virtudes e fragilidade do processo de extensão rural universitária}

Naturalmente uma análise desse tipo tende a iniciar por salientar as virtudes dessa experiência. Existe uma concretude desse projeto. A feira virtual do TECSOL ocorre todo o sábado desde 2015. Esse é um fato incontestável, ou seja, qualquer avaliação que se faça tem que considerar que se avançou do campo das ideias e das propostas para algo factível e que realmente impacta na vida de agricultores e consumidores.

Os grupos de economia solidária rurais são uma expressão atual dos laços fortes que unem as comunidades rurais como a religião, o sentido de pertencimento comunitário ou a própria expressão da identidade sociocultural. Esse amalgama social propicia elementos de confiança comunitária que impulsionam positivamente o processo.

A feira virtual movimenta alimentos que chegam na casa dos consumidores, e esses através das compras, viabilizam a vida dos agricultores. Existe um processo de acesso ao alimento agroecológico pelos consumidores que pode ser considerado um privilégio de poucas pessoas no espaço urbano, e consequentemente, os agricultores vendem seu alimento e conseguem recursos financeiros que estabilizam suas propriedades. 
É possível a constatação de que esse circuito curto de comercialização gerou um processo de acumulação solidária bastante distinto do que pode ser observado no mercado geral do entorno da experiência que continua com características hostis. Esse fato condiz com o pensamento de Cruz (2011) que afirma que os processos de economia solidária necessariamente devem conter esses elementos.

Cabe salientar que o projeto da feira não se caracteriza por se um processo executado exatamente como planejado em sua nascença. Na verdade, existem problemas cotidianos que acabam sendo resolvidos com o processo em andamento. Vamos comentar os percalços na sequência, mas é importante considerar que a capacidade de solucionar impasses não previstos é um mérito a ser dado aos atores envolvidos. Essa habilidade ajuda a manter a comercialização funcionando desde 2015. Destaca-se que as técnicas da economia solidária se apoiam nas relações sociais de interreconhecimento e consequentemente ganham vantagens na construção de alternativas aos problemas do cotidiano (GAIGER, 2004).

Do ponto de vista dos agricultores a comercialização na feira virtual fortalece o processo de transição agroecológica. Os três perfis de agricultores fornecedores (aposentado, agricultor familiar substituindo o tabaco e os neorurais) possuem a pressão, através da propaganda, da produção convencional de alimentos dentro dos espaços de sua convivência como a comunidade rural, o sindicato ou mesmo a família. A manutenção de uma produção de alimentos de base ecológica é um indicador da mudança do pensamento desses atores. Isso ocorre a partir da construção coletivamente do conhecimento do itinerário técnico de cada cultivo ou criação. Se torna um saber dialogado sistematicamente entre as pessoas e a natureza.

Não é um processo simples e padronizado, está envolto em um conjunto de alternativas e dificuldades que devem ser paulatinamente vencidas. A transição agroecológica não pode ser considerada um procedimento único e estandardizado. Nesse, o agricultor se torna sujeito na construção de caminhos multilineares que levam a adoção de princípios ecológicos dentro da agricultura (COSTABEBER, 1998; BUTTEL, 1995).

A extensão rural universitária apoia exatamente esses aspectos aproximando os agricultores e seus grupos de economia solidária de outros grupos de pessoas com experiências parecidas e constituindo redes de construção do conhecimento. 
Do ponto de vista dos estudantes, que vivem o papel de extensionistas, eles entendem que a experiência do trabalho junto aos agricultores cumpre uma lacuna deixada pela academia ao aproximá-los da realidade concreta da agricultura familiar. Nesse sentido a sua ação passa a ser verdadeira e concreta como um ator da extensão rural, possibilitando uma sensação de realização profissional. Eles expressam que lidar diretamente com os agricultores em uma situação verdadeira, no dia a dia, vivenciando as dificuldades e as alegrias, produz uma condição de melhor entendimento do rural.

A metodologia de ação da equipe de extensão rural universitária toma como ponto básico que os agricultores possuem diferentes saberes acumulados. Isso fica ainda mais patente pela sua diversidade de tipologias de formação. Esse saber diferenciado abre um grande leque de possibilidades na construção de caminhos multilineares de transição agroecológica.

A técnica do "encontrão", por exemplo, é um artifício de diálogo de saberes. Os extensionistas preparam o ambiente e a infraestrutura para que ocorra o encontro dos agricultores e, a partir de perguntas problematizadoras, potencializam o debate dasdificuldades e das possibilidades de solução. O conhecimento é compartilhado e recombinado. Nesse ínterim os extensionistas também expressam seu saber acumulado nos estudos universitários e auxiliam na produção de novos saberes. Um clássico diálogo de saberes.

O exercício prático das atividades juntos aos grupos de economia solidária rurais aperfeiçoam a formação dos extensionistas. Esse caminho de formação tende a produzir profissionais de mediação social com características participativas, agroecológicas e solidárias, possivelmente sendo esse o maior mérito do projeto.

Outro indicador de transição agroecológico percebido na experiência é o rompimento da noção compartimentada produzida pela modernização da agricultura onde o homem, o solo, a água e as plantas são vistos de forma individualizadas e independentes.

Aproximando das ideias de Noogard (1989) os agricultores de base ecológica desenvolvem noção sistêmicas para o entendimento da agricultura, onde o ato de pensar na saúde e nutrição dos solos é também pensar na nutrição de plantas ou na qualidade da alimentação das criações. Essa percepção de que as 
pessoas estão imersas dentro de sistema ecológico e suas ações são auto dependentes é uma das características agroecológicas vislumbradas nos agricultores envolvidos no projeto.

Como fragilidades do processo de extensão rural universitária possivelmente o maior limite esteja intimamente ligada a maior virtude, ou seja, os estudantes. Todas as ações diretas junto aos agricultores são realizadas pelos estudantes tendo uma supervisão dos professores.

Essa característica propicia uma exposição do aluno que ainda não tem uma formação completa o que propicia, muitas vezes, uma insegurança na orientação tecnológica e/ou metodológica. Esse fato varia entre os alunos, devido ao grau de maturidade ou experiências anteriores, mas sempre aparece como um limite do trabalho concreto através da expressão de insegurança na condução do processo.

Os professores pela sua experiência aconselham trilhos metodológicos e tecnológicos para as ações de extensão rural universitária, mas existe o limite da não participação em todos os momentos da interface impede uma visão sistêmica do cotidiano.

Em outro aspecto, a equipe de extensão rural universitária é multidisciplinar sendo fortemente enviesada pelos alunos da Agronomia, mas com elementos da Veterinária e Gestão Ambiental. Isso permite o acesso a vários campos de conhecimento. Mas, muitos alunos têm dificuldade de aproximarem seus objetos de estudo disciplinares da realidade da agricultura familiar. Isso é um fato na Agronomia, porém muito forte na Veterinária que na atualidade enfatiza a aproximação clínica individualizada em detrimento ao trabalho com rebanhos. Essa situação produz um conflito interno profissional e amplia o grau de insegurança.

Os cursos universitários citados possuem um desenho de curriculum para serem de turno integral. Esse limitador também dificulta o deslocamento dos alunos para as visitas semanais aos agricultores. Isso exige um planejamento prévio do estudante abrindo espaço em sua carga horária, no momento da matrícula, de ao menos um a dois turnos completos para deslocamento ao rural. Muitos alunos interessados desistem quando confrontados com esse limite. Agregado ao fato de trabalharmos em uma equipe que se deslocando junta, isso exige uma grande concatenação de datas e momentos de saída da Universidade. Na prática não é algo simples. 
Outro complicador operacional é a dependência de um servidor para conduçãodo veículo do projeto (que pertence a Universidade). Esse fato que pode parecer banal e protocolar, mas se caracteriza como um "calcanhar de Aquiles" na viabilização das saídas e sempre consome tempo e esforço da equipe. Muitas vezes a indisponibilidade do motorista inviabiliza o projeto durante várias semanas do ano.

Outra fonte de fragilidade do processo é o relacionamento entre os agricultores. Eles possuem fortes vínculos sociais dentro das comunidades rurais, porém o elemento da economia solidária emergiu apenas recentemente. Ou seja, eles são comunitários em sua essência e estão em processo de entendimento dos princípios da economia solidária. Isso produz, por vezes, interpretações simplificadas do processo de comercialização e dos princípios da economia solidária.

Em alguns momentos os agricultores produzem comportamentos enviesados, incitados pelo ambiente externo, de sobretaxação de seus produtos pelo atributo de ser orgânico ou de apresentação de qualidade inferior dentro do mesmo argumento. Esses fatos ferem uma lógica solidária e se aproximam de uma noção de "nicho de mercado" que está mais afeta ao mercado geral capitalista. Porém cabe entender esses momentos como partes de um processo que não está finalizado e passível de correção dos caminhos no intuito da manutenção da lógica solidária. Passa a ser um tema constante dentro da ação da extensão rural universitária.

Essa mesma contaminação da lógica do mercado geral externo pode ser vista no comportamento dos consumidores. Mesmo tendo um perfil diferenciado, formado principalmente por pessoas da Universidade e com possibilidade de fácil acesso aos conceitos da economia solidária, em alguns momentos são vislumbrados comportamentos típicos de consumidores do mercado geral capitalista como, por exemplo: a exigência de padrão de tamanho grande nos produtos (esquecendo as características diversificadas de uma agricultura de base orgânica), exigência de oferta em períodos de entressafra (muitas vezes inexequível por parte dos agricultores agroecológicos) e a pressão pelo uso de selos de orgânicos perdendo o necessário caráter de confiança que se deve ter nos processos da economia solidária.

Do mesmo modo que com os agricultores é preciso a compreensão que os consumidores são bombardeados por informações advindas do mercado geral 
capitalista e tendem a não refletir as profundas diferenças que existem em mercados norteados pelos princípios da economia solidária.

\section{CONCLUSÕES}

A reflexão sobre o projeto TECSOL, com foco na extensão rural universitária, tem como metas a construção de princípios que possam auxiliar na continuidade e aprimoramento do processo em andamento, e também, transcender esses princípios para outras experiências semelhantes que ocorrem em variados espaços empíricos. Nesse sentido busca o diálogo com elementos de outras vivências na construção de possíveis insights.

Na perspectiva teórica a ligação entre os estudos de agroecologia e economia solidária ainda é tênue e incipiente. A análise dos elementos teóricos dos dois campos permite, de forma contundente, encontrar pontos fortes de contato e lógicas muito próximas. Porém, são campos que emergiram em disciplinas afastadas que carecem de análises com profundidade e esforço teórico em sua aproximação. No exercício pragmático dentro da experiência essas diferenças não são perceptíveis, mas uma análise mais atenta pode-senotar esses elementos.

A experiência da extensão rural universitária, dentro do TECSOL, produz como pontos positivos a formação de estudantes extensionistas com características participativas, agroecológicas e solidárias. Esse é um elemento central dentro de esforço acadêmico. Outro ponto é a concretude da experiência dentro do tempo e a própria superação solidária das dificuldades encontradas. Um último destaque positivo pode ser dado é a impulsão, através da extensão rural universitária, do processo de transição agroecológica mesmo com os variados limites intrínsecos das características do processo.

Os grandes limites da extensão rural universitária estão ligados a insegurança dos jovens alunos que enfrentam a ação de frente, mas esse é uma característica inerente do processo, e a questão da pressão externa.

A transição agroecológica em um ambiente de economia solidaria se configura como um caminho contra hegemônico da modernização da agricultura e do mercado geral capitalista. Esse ambiente externo hostil cotidianamente bombardeia os agricultores e consumidores com ideias e ações que enviesam 
os princípios ecológicos e solidários. Isso pode ser considerado natural dentro de um campo de batalha pelos projetos sociais, mas exige um esforço coletivo e constante de análise e ajustes para a manutenção desse processo.

\section{REFERÊNCIAS}

ALMEIDA, J. A construção social de uma nova agricultura: tecnologia agrícola e movimentos sociais no sul do país. Porto Alegre: Ed. Universidade, 1999.

ALTIERI, M. Agroecologia: as bases científicas da agricultura alternativa. Rio de Janeiro: PTA; FASE, 1989.

BEAUD, S.; WEBER, F. Guia para a análise de campo: produzir e analisar dados etnográficos. Petrópolis: Vozes, 2007.

BONI, V.; QUARESMA, S.J. Aprendendo a entrevistar: como fazer entrevistas em ciências sociais. Revista Eletrônica de Pós-Graduação em Sociologia Política da UFSC, Florianópolis, v.2, n.1, p.3, jan./jul. 2005. Disponível em: <http://www. emtese.ufsc.br>. Acesso em: 01 fev. 2007.

BUTTEL, F. Transiciones agroecológicas en el siglo XX: analises preliminar. Agricultura y Sociedad, n. 74, p. 9-37, 1995.

CAPORAL, F.R. La extensión agraria del sector público ante los desafíos del desarrollo sostenible: el caso de Rio Grande do Sul, Brasil. 1998. 517p. Tese (Doutorado)-Programa de Doctorado en Agroecología, Campesinado e Historia, ISEC-ETSIAN, Universidad de Córdoba, Córdoba, 1998.

CAPORAL, F.R.; COSTABEBER, J.A. Análise multidimensional da sustentabilidade: uma proposta metodológica a partir da agroecologia. Agroecologia e Desenvolvimento Rural Sustentável, Porto Alegre, v.3, n.3, p.70-85, jul./set. 2002.

COSTABEBER, J.A. Accióncolectiva y transición agroecológicaen Rio Grande do Sul, Brasil. 1998. 434p. Tese (Doutorado)-Programa de Doctorado en Agroecología, Campesinado e Historia, ISEC-ETSIAN, Universidad de Córdoba, Córdoba, 1998. 
CORAGGIO, J. L. La economía social como vía para otro desarrollo social. Documento de lanzamiento del debate sobre "distintas propuestas de economía social" - Red de Políticas Sociales,2002.Disponível em: <http://municipios.unq. edu.ar/modules/mislibros/archivos/laeconomia.pdf>. Acesso em: 5 abr. 2015.

COTRIM, D. S.; CANEVER, M. D. A caracterização dos agricultores familiares que cultivam tabaco no Território Centro-Sul/RS. Revista Redes, Santa Cruz do Sul, v. 3, n. 21, p.239-267, 30 set. 2016. Disponível em:

<https://online.unisc.br/seer/index.php/redes/article/view/7570>. Acesso em: 30 set. 2016.

CRUZ, A. A acumulação solidária: os desafios da economia associativa sob a mundialização do capital. In: Revista Cooperativismo \&Desarrollo, Bogotá, n.99, 2011.

DAL SÓGLIO, F.; LEMOS, V.D. da C. Desenvolvimento rural no Brasil: uma visão ecológica e a interação com ensino e pesquisa. In.: ALMEIDA, J. (Org). Políticas públicas e desenvolvimento rural: percepções e perspectivas no Brasil e Moçambique. Porto Alegre: UFRGS. PGDR.2009. 267p.

DAL SÓGLIO. Desenvolvimento, agricultura e agroecologia: qual a ligação? [s. L.: s. n.], 2012.

GAIGER, L. I. et al. Sentidos e experiências da economia solidária no Brasil. Porto Alegre: UFRGS, 2004.

GIL, A. C. Como elaborar projetos de pesquisa. São Paulo: Atlas, 2002.

GLIESSMAN, S.R. Agroecologia: processos ecológicos em agricultura sustentável. 3.ed. Porto Alegre: Ed. da UFRGS, 2005.

IBGE. Censo Agropecuário 2006. Rio de Janeiro,2010. Disponível em: <http://www. ibge.gov.br>. Acessoem: 01 fev. 2011.

LONG, N. Development sociology:actor perspectives. London: Routledge, 2001.

MOLINA, M.G. Introduccion a la agroecologia. Madrid: Sociedade Española de Agricultura Ecológica, 2011. 70p. 
NORGAARD, R. B. A base epistemológica da agroecologia. In: ALTIERI, M. A. (Ed.). Agroecologia: as bases científicas da agricultura alternativa. Rio de Janeiro: PTA:FASE, 1989. p. 42-48.

PISTELLI, R.; ZERBINI, F. A comercialização no contexto do comércio ético e solidário. São Paulo: Faces do Brasil, 2004. Disponível em:<http://facesdobrasil. org.br/midiateca/doc_view/54-a-comercializacao-no-contexto-do-comercioetico-e-solidario.raw?tmpl=component>. Acesso em: 10 abr. 2015.

RAZETO, L. Los caminos de la economía de solidaridad. Buenos Aires: LumenHvmanitas. 1997

SINGER, P. Economia solidária: um modo de produção e de distribuição. In: SINGER, Paul; SOUZA, André Ricardo et al. Economia solidária no Brasil: a autogestão como resposta ao desemprego. São Paulo: Contexto. 2000.

TIRIBA, L. Economia popular e cultura do trabalho: pedagogia(s) da produção associada. Ijuí: Unijuí. 2001.

Data de recebimento: 26 de outubro de 2017.

Data de aceite para publicação: 08 de janeiro de 2018. 